\title{
Life Prediction of Existing Concrete Structures in Acid Rain Environment
}

\author{
Ying Huang \\ ${ }^{1}$ Department of Architecture and Civil Engineering, Jiangxi Science \& Technology Normal University, \\ Nanchang, 330013, China \\ aemail: huangying7871@163.com
}

Keywords: Acid Rain Erosion-Carbonization Model; the Neutralization Depth; Lifetime Prediction

\begin{abstract}
In the paper based on diffusion theory the acid rain erosion-carbonization model was established. The model parameters were analyzed and the model was solved by MATLAB software. At same time the failure criteria of existing concrete structure in acid rain area was developed and the life prediction method was proposed. Finally, combined with the acid rain feature in Nanchang the multi-storey teaching building life was predicted to prove the validity of the model. The calculation showed the acid rain damage to the building in Nanchang is more serious. It should be taken seriously enough.
\end{abstract}

\section{Introduction}

Acid rain is the rain, snow, frost, mist or other forms of atmospheric precipitation whose $\mathrm{PH}$ value is less than 5.6[1]. The erosion of acid rain on the concrete structure has two ways. On the one hand, acid rain directly corroded the concrete structures. On the other hand, acid rain can make the concrete structures neutralization, which caused steel corrosion and reduce the service behavior. The major energy in China is coal. With the rapid development of economy, the coal consumption is increasing. And SO2 emissions continue to grow, which make China become the third largest acid rain area after Europe and North America. Under the effect of the multiple factors-acid rain, carbonization and load-the service behavior of concrete structures in acid rain area continue to deteriorate. But the damage on the concrete structures caused by multiple factors is not a simple superposition of a single factor. So it is necessary to carry out the research work on the working state and life prediction of concrete structures in acid rain area under the action of multiple factors.

The scholars[2-5] at home and abroad carried out a series of experimental and theoretical research works on acid rain erosion mechanism. Reference $[6,7]$ is about concrete carbonation regularity under stress condition. The neutralization mechanism and regularity of concrete structures under the coupling action of stress, carbonation and acid was qualitatively analyzed in reference [8]. However, research on service performance of concrete structures in acid rain area considering carbonation is few, the research needs to be deepened. The research on the working state assessment and life prediction of existing concrete structures in acid rain is rare. In the paper based on diffusion theory the acid rain erosion-carbonization model was established. The model parameters were analyzed and the model was solved by MATLAB software. At same time the failure criteria of existing concrete structure in acid rain area was developed and the life prediction method was proposed. Finally, combined with the acid rain feature in Nanchang the multi-storey teaching building life was predicted to prove the validity of the model. The calculation showed the acid rain damage to the building in Nanchang is more serious. It should be taken seriously enough.

\section{Concrete neutralization mechanism and model}

Carbonization is the physical and chemical process that the cement hydration in concrete reacted with $\mathrm{CO}_{2}$ and decomposed carbonate compounds and other substances. The main chemical equation of concrete carbonation are as follows: 


$$
\begin{aligned}
& \mathrm{Ca}(\mathrm{OH})_{2}+\mathrm{H}_{2} \mathrm{CO}_{3}=\mathrm{CaCO}_{3}+2 \mathrm{H}_{2} \mathrm{O} \\
& \mathrm{CSH}+3 \mathrm{CO}_{2}=3 \mathrm{CaCO}_{3}+2 \mathrm{SiO}_{2}+3 \mathrm{H}_{2} \mathrm{O} \\
& \mathrm{C}_{3} \mathrm{~S}+3 \mathrm{CO}_{2}+\gamma \mathrm{H}_{2} \mathrm{O}=3 \mathrm{CaCO}_{3}+\mathrm{SiO}_{2} \cdot \gamma \mathrm{H}_{2} \mathrm{O} \\
& \mathrm{C}_{2} \mathrm{~S}+2 \mathrm{CO}_{2}+\gamma \mathrm{H}_{2} \mathrm{O}=2 \mathrm{CaCO}_{3}+\mathrm{SiO}_{2} \cdot \gamma \mathrm{H}_{2} \mathrm{O}
\end{aligned}
$$

In concrete carbonation process $\mathrm{CO}_{2}$ diffusion rate in concrete pores is the control factor ${ }^{[9]}$. And $\mathrm{CO}_{2}, \mathrm{CH}, \mathrm{CSH}$ and non-hydrated silicate compounds is in accordance with law of conservation of mass. Based on the diffusion theory the carbonation model was established by Greek scholars V. G. Papadakis. Generally the length size of concrete member is large than the section size, the threedimensional problem was simplified as a two-dimensional problems of $\mathrm{CO}_{2}$ diffusion in concrete. Assuming that the ambient temperature and humidity is relatively stable, the active ingredient in cement completely hydrated. Then the carbonization model is as follows:

$$
\begin{aligned}
& \frac{\partial}{\partial t}\left[\mathrm{CO}_{2}\right]=D_{\mathrm{CO}_{2}}\left(\frac{\partial^{2}\left[\mathrm{CO}_{2}\right]}{\partial x^{2}}+\frac{\partial^{2}\left[\mathrm{CO}_{2}\right]}{\partial y^{2}}\right)-\left(K_{\mathrm{CH}}+3 K_{\mathrm{CSH}}\right)\left[\mathrm{CO}_{2}\right] \\
& \frac{\partial}{\partial t}[\mathrm{CH}]=-K_{\mathrm{CH}}\left[\mathrm{CO}_{2}\right] \\
& \frac{\partial}{\partial t}[\mathrm{CSH}]=-K_{\mathrm{CSH}}\left[\mathrm{CO}_{2}\right]
\end{aligned}
$$

Where, $D_{\text {co2 }}$ is $\mathrm{CO}_{2}$ diffusion coefficient in concrete; $\left[\mathrm{CO}_{2}\right],[\mathrm{CH}],[\mathrm{CSH}$ respectively refer to the concentration of $\mathrm{CO}_{2}, \mathrm{CH}, \mathrm{CSH} ; K_{C H}, K_{C S H}$ respectively refer to the carbonation reaction constant of $\mathrm{CH}, \mathrm{CSH}\left(K_{\mathrm{CH}}, K_{C S H}=7.8 \times 10^{-3} \mathrm{~m}^{3} \cdot(\mathrm{mol} \cdot \mathrm{s})^{-1}\right) ; x, y$ is respectively distance to concrete surface; $t$ is carbonization time.

Acid rain is rich in $\mathrm{H}^{+}$ions. When acid rain drop down the concrete surface and into the concrete pores the neutralization reaction with $\mathrm{H}^{+}$ions and the cement hydration occurred, which make the $\mathrm{PH}$ of concrete decrease and rebar depassive. The main chemical equations of acid rain erosion are as follows:

$$
\begin{aligned}
& \mathrm{Ca}(\mathrm{OH})_{2}+2 \mathrm{H}^{+} \rightarrow \mathrm{Ca}^{2+}+2 \mathrm{H}_{2} \mathrm{O} \\
& n \mathrm{CaO} \cdot \mathrm{mSiO}_{2} \cdot 2 n \mathrm{H}_{2} \mathrm{O}+2 n \mathrm{H}^{+} \rightarrow n \mathrm{Ca}^{2+}+m \mathrm{SiO}_{2}+n \mathrm{H}_{2} \mathrm{O} \\
& n \mathrm{CaO} \cdot \mathrm{mAl}_{2} \mathrm{O}_{3}+2 n \mathrm{H}^{+} \rightarrow n \mathrm{Ca}^{2+}+\mathrm{mAl}_{2} \mathrm{O}_{3}+n \mathrm{H}_{2} \mathrm{O}
\end{aligned}
$$

In the process of acid rain $\mathrm{H}^{+}$ions transport in concrete by diffusion. When the active ingredient in cement completely hydrated the $\mathrm{H}^{+}$ions diffusion model is as follows:

$$
\begin{aligned}
& \frac{\partial}{\partial t}\left[H^{+}\right]=D_{H^{+}}\left(\frac{\partial^{2}\left[H^{+}\right]}{\partial x^{2}}+\frac{\partial^{2}\left[H^{+}\right]}{\partial y^{2}}\right)-\left(K_{C H}^{\prime}+3 K_{C S H}^{\prime}\right)\left[H^{+}\right] \\
& \frac{\partial}{\partial t}[C H]=-K_{C H}^{\prime}\left[H^{+}\right] \\
& \frac{\partial}{\partial t}[C S H]=-K_{C S H}^{\prime}\left[H^{+}\right]
\end{aligned}
$$

Where, $\mathrm{D}_{\mathrm{H}}{ }^{+}$is $\mathrm{H}^{+}$diffusion coefficient in concrete; $K_{\mathrm{CH}}, K_{\mathrm{CSH}}$ respectively refer to the reaction constant of $\mathrm{CH}, \mathrm{CSH}$ in acid rain solution $\left(\mathrm{K}_{\mathrm{CH}}, \mathrm{K}_{\mathrm{CSH}}=7.8 \times 10^{-3} \mathrm{~m}^{3} \cdot(\mathrm{mol} \cdot \mathrm{s})^{-1}\right)$; $\left[\mathrm{H}^{+}\right]$is the concentration of $\mathrm{H}^{+}$.

\section{Solution of acid rain-carbonization model}

Based on gas diffusion mechanisms in porous solid media $\mathrm{CO}_{2}$ diffusion coefficient in concrete is related to concrete media status and $\mathrm{CO}_{2}$ dynamic characteristics. That is, it is effected by concrete properties (strength, stress state) and environmental factors (temperature, relative humidity). The larger concrete strength is, the more concrete dense is. The smaller the porosity is, the slower gas diffusion rate is. When the concrete is in the state of compression the pore volume of concrete decreases and gases diffuse slowly. On the contrary when the concrete is in the state of 
tension the pore volume of concrete increases and gases diffuse quickly. Based on thermodynamic principles the higher the temperature is, the more intense molecular motion is and the faster gas diffusion rate is. The bigger the relative humidity is, the higher pore water saturation in concrete is and the slower the gas diffusion rate is. So calculation model of $\mathrm{CO}_{2}$ diffusion coefficient in concrete was established as follows.

$$
D_{\mathrm{CO}_{2}}=k_{\text {fcuk }} k_{\sigma} k_{T} k_{R H}
$$

Where, $k_{f c u k}$ is the strength correlation coefficient of $\mathrm{CO}_{2}$ diffusion coefficient, the experimental data in references [11 13] was fitted and $k_{f c u k}=\left(5.02-1.26 \ln f_{c u k}\right) \times 10^{-8}, f_{c u k} \leq 50 M P a ; k_{\sigma}$ is the stress correlation coefficient of $\mathrm{CO}_{2}$ diffusion coefficient, $k_{\sigma}=1.01362-0.01386 \sigma_{c}, k_{\sigma}=0.99261+0.07911 \sigma_{t}{ }^{[14]}, \quad \sigma_{t}, \quad \sigma_{c}$ respectively is tensile stress and compressive stress; $k_{T}$ is the temperature correlation coefficient of $\mathrm{CO}_{2}$ diffusion coefficient, $k_{T}$ $=0.02 K-4.86^{[15]} ; k_{R H}$ is the relative humidity correlation coefficient of $\mathrm{CO}_{2}$ diffusion coefficient, $k_{R H}=\left((1-R H) /\left(1-R H_{0}\right)\right)^{2.2}, \mathrm{RH}_{0}=0.7^{[16]}$.

$\mathrm{H}^{+}$diffusion coefficient in concrete is related to concrete water-cement ratio, stress state, temperature and humidity. Refer to the chloride ion diffusion coefficient $\mathrm{H}^{+}$diffusion coefficient in concrete is as follows.

$$
D_{H^{+}}=10^{(-12.06+2.4 W / C)} \cdot k_{\sigma}^{\prime} \cdot k_{T}^{\prime} \cdot k_{R H}^{\prime}
$$

Where, W/C is concrete water-cement ratio; $k_{\sigma}^{\prime}$ is the strength correlation coefficient of $\mathrm{H}+$ diffusion coefficient, $k_{\sigma}{ }_{\sigma}=1-1.2463 \delta_{c}+1.9091 \delta_{c}{ }^{2}$ or $k_{\sigma^{\prime}}{ }^{\prime}=1-0.129 \delta_{t}+0.8291 \delta_{t}{ }^{2}{ }^{[19]}, \sigma_{t}, \sigma_{c}$ respectively is the ratio of tensile stress and ultimate tensile stress, the ratio of compressive stress and ultimate compressive stress; $k_{T}{ }_{T}$ is the temperature correlation coefficient of $\mathrm{H}^{+}$diffusion coefficient, $\quad k_{T}^{\prime}=\exp \left(U / R\left(1 / T_{\text {ref }}-1 / T\right)\right)^{[20],} U$ is activation energy in diffusion $\operatorname{process}(=35000 \mathrm{~J} / \mathrm{mol}), R$ is gas constant $(8.314472 \mathrm{~J} / \mathrm{K} \mathrm{mol}), T_{\text {erf }}=293 \mathrm{~K} ; k_{R H}$ is relative humidity correlation coefficient of $\mathrm{H}^{+}$diffusion coefficient ${ }^{[16]}, k^{{ }^{\prime}{ }_{H}}=\left[1+(1-h)^{4} /\left(1-h_{c}\right)^{4}\right]^{-1}, h_{c}=0.75$.

The main mineral composition of Portland cement clinker is $\mathrm{C}_{3} \mathrm{~S}, \mathrm{C}_{2} \mathrm{~S}, \mathrm{C}_{3} \mathrm{~A}$ and $\mathrm{C}_{4} \mathrm{AF}$. And $m_{c 3 s}=55 \%, m_{c 2 s}=20 \%, m_{c 3 A}=13 \%, m_{c 4 A F}=9 \%$. According to cement hydration reaction equation the neutral substance concentration in fully-hydrated concrete is as follows. $\left[\mathrm{C}_{3} \mathrm{~S}\right]^{0}=0,\left[\mathrm{C}_{2} \mathrm{~S}\right]^{0}=0$, $[\mathrm{CSH}]^{0}=0.5\left[\mathrm{C}_{3} \mathrm{~S}\right]^{0}+0.5\left[\mathrm{C}_{2} \mathrm{~S}\right]^{0}, \quad[\mathrm{CH}]^{0}=1.5\left[\mathrm{C}_{3} \mathrm{~S}\right]^{0}-4\left[\mathrm{C}_{4} \mathrm{AF}\right]^{0}+0.5\left[\mathrm{C}_{2} \mathrm{~S}\right]^{0}-\left[\mathrm{C}_{3} \mathrm{~A}\right]^{0}+[\mathrm{CSH}]^{0}$. When cement hydrated completely the substances reacted with $\mathrm{CO}_{2}$ and $\mathrm{H}^{+}$are $\mathrm{CH}$ and $\mathrm{CSH}$. According to concrete carbonation reaction equation $\mathrm{CO}_{2}$ consumption per unit volume of fully-hydrated concrete can be calculated, $m_{\mathrm{CO} 2}=[\mathrm{CH}]^{0}+3[\mathrm{CSH}]^{0}$. According to acid rain erosion reaction equation $\mathrm{H}^{+}$consumption per unit volume of fully-hydrated concrete can be calculated, $m_{\mathrm{H}^{+}}=[\mathrm{CH}]^{0}$.

When the acid rain erosion and carbonization in concrete structures occur at the same time the initial conditions of acid rain erosion-carbonization model are as follows.

$\left[\mathrm{CO}_{2}(0, x)\right]=0 ;\left[\mathrm{H}^{+}(0, x)\right]=0 ;[\mathrm{CH}(0, x)]=[\mathrm{CH}]^{0} ;[\mathrm{CSH}(0, x)]=[\mathrm{CSH}]^{0}$.

When the acid rain erosion and carbonization in concrete structures occur at the same time, assuming erosion of $\mathrm{CO}_{2}$ and acid rain is one-side, the boundary conditions of acid rain erosioncarbonization model are as follows.

$$
\begin{gathered}
{\left[\mathrm{CO}_{2}(t, 0)\right]=\left[\mathrm{CO}_{2}\right]^{0} ;\left[\mathrm{CO}_{2}(t, L)\right]=0 ;} \\
{[\mathrm{CH}(t, 0)]=0 ;[\mathrm{CH}(t, L)]=[\mathrm{CH}]^{0} ;} \\
{[\mathrm{CSH}(t, 0)]=0 ;[\mathrm{CSH}(t, L)]=[\mathrm{CH}]^{0} ;} \\
{\left[\mathrm{H}^{+}(t, 0)\right]=\left[\mathrm{H}^{+}\right]^{0} ;\left[\mathrm{H}^{+}(t, L)\right]=0 ;}
\end{gathered}
$$

Where, $t$ is time; $L$ is the specimen thickness.

The acid rain erosion-carbonization model can be solved by the finite different method in the two-dimensional conditions. Forward difference was adopted to time and central difference was adopted to space. The partial differential equations were solved based on MATLAB software.

\section{Failure criteria of concrete structure}

When reinforced bar began corroded the concrete structure had reached the durability limit state based on code for durability design of concrete structures (GBT50476-2008) ${ }^{[22]}$. While the passive film on reinforced surface was damaged the reinforced was in the active state. When both water and 
oxygen are sufficient reinforced can be corroded. The study ${ }^{[17]}$ showed that, when PH was less than or equal to 9 passive film on reinforced surface in concrete was completely destroyed and reinforced was in fully activated state. When $\mathrm{PH}$ was larger than or equal 11.5, the integral passive film was formed on reinforced surface. Assumed the passive film on reinforced surface was completely destroyed reinforced began to corrode. So when PH is less than or equal to 9 reinforced began to corrode and the concrete is in the neutral state. The PH calculation formula is as follow ${ }^{[17]}$.

$$
\mathrm{PH}=-\lg K_{w}+\lg \left(4.32 \times 10^{-2} \times[\mathrm{CH}] /[\mathrm{CH}]^{0}\right)
$$

Where, $K_{w}$ is ionization constants of water, $K_{w}=1 \times 10^{-14}$.

\section{Acid rain erosion-carbonization model validation}

The environmental parameters-PH value of acid rain (4.55), the annual average temperature (290.65K), the annual average relative humidity (78\%), the average content of $\mathrm{CO}_{2}$ in the air (volume percentage $0.0385 \%$ ) and the average content of $\mathrm{SO}_{2}\left(46 \mu \mathrm{g} / \mathrm{m}^{3}\right)$ were determined according to the acid rain characteristics and air quality statistics in Nanchang from 2009 to $2013^{\text {[23] }}$. The multi-storey teaching building was built in 1994. The main structure is cast-in-situ frame structure. C20 concrete was used in roof slab, the cubic compressive strength of concrete in 28d is $22.0 \mathrm{MPa}$, the water cement ratio is 0.5 , the amount of cement is $400 \mathrm{Kg}$, sand ratio is $34 \%$, the concrete cover thickness is $15 \mathrm{~mm}$. C25 concrete was used in frame column, the cubic compressive strength of concrete in $28 \mathrm{~d}$ is $26.7 \mathrm{MPa}$, the water cement ratio is 0.45 , the amount of cement is $400 \mathrm{Kg}$, sand ratio is $36 \%$, the concrete cover thickness is $25 \mathrm{~mm}$. Take the roof slab in bearing chair, the roof slab in mid-span, external column as the object the rain erosion- carbonization model was adopted to calculate neutralization depth every decade (see table 1).

Table 1 the neutralization depth

\begin{tabular}{|c|c|c|c|}
\hline \multicolumn{4}{|c|}{ the neutralization depth $(\mathrm{mm})$} \\
\hline Time (year) & the roof slab in bearing chair & the roof slab in mid-span & external column \\
\hline 10 & 10.6 & 7.1 & 4.9 \\
\hline 20 & 15.0 & 10.1 & 7.0 \\
\hline 30 & 18.4 & 12.4 & 8.6 \\
\hline 40 & 21.3 & 14.3 & 9.9 \\
\hline 50 & 23.8 & 16.0 & 11.1 \\
\hline
\end{tabular}

Table 1 showed that the neutralization depth exceeds the concrete layer thickness in about 20 year at the bearing chair of roof slab and the neutralization depth exceeds the concrete layer thickness in about 45 year at the mid-span of roof slab. According to failure criteria of concrete structure the lifetime of multi-storey teaching building is about 20 year. So the acid rain damage to the building in Nanchang is more serious. It should be taken seriously enough.

\section{Conclusion}

(1)The acid rain erosion-carbonization model was developed based on the diffusion theory. The model parameters- $\mathrm{CO}_{2}$ diffusion coefficient, $\mathrm{H}^{+}$diffusion coefficient in concrete were analyzed. The boundary conditions and initial conditions were determined. The neutralization depth calculation method of existing concrete structures in acid rain area was obtained.

(2)The lifetime calculation method of existing concrete structures in acid rain area was obtained by determining the failure criteria of concrete structure.

(3) The acid rain erosion-carbonization model in the paper was used to calculate neutralization depth of the multi-storey teaching building in Nanchang. The lifetime of the multi-storey teaching building is about 20 years. So the acid rain damage to the building in Nanchang is more serious. It should be taken seriously enough. 


\section{Acknowledgement}

In this paper, the research was sponsored by Youth Science and Technology Research Project in Jiangxi Province Education Department (Project No. GJJ14597), Open fund of Nation Engineering Laboratory for High Speed Railway Construction (Project No.HSR2013011) and the key cultivating base of the concrete structure mechanics behavior and control research (Project No.300098010309).

\section{References}

[1]Zhang Guanghua, Zhao Dianwu. Acid rain[M].Beijing:China environment science press,1989 [2]Tsutomu Kanazu, Takuro Matsumura, Tatsuo Nishiuchi. Effect of Simulated Acid Rain on Deterioration of Concrete [J].Acid Rain,2001:1481-1486

[3]Yingzi Zhang, Yingfang Fan, Hongnan Li. Influence of Simulated Acid Rain Corrosion on the Uniaxial Tensile Mechanical Properties of Concrete[J]. International Journal of Corrosion, 2012

[4]Niu Ditao, Zhou Haoshuang, Niu Jiangang. Investigation of neutralization of concrete under loads by accelerated acid rain test[J].bulletin of the Chinese ceramic society,2009,28(3): 411-415

[5]Hu Xiaobo, Long Ting, Tao Xinming. Influence of a simulated acid rainfall on menchanical properties of C50 concrete[J]corrosion science and protection technology, 2009,21(4):380-383

[6] Castel A , Francccois R , Arliguie G. Effect of loading on carbonation penet ration in reinforced concrete element s [ J ].Cement and Concrete Research, 1999,29 (4) :561.

[7]Tian Hao, Li Guoping, Liu Jie. Experimental research on carbonation of forced concrete specimens[J].Journal of Tongji university(natural science)2010,38(2):200-204,213

[8]Xu Congfa, Cao Shuangyin, Fan Shenlong. Experimental study on the concrete neutralization under stress and carbonization and acid rain[J].China civil engineering journal,2014,47(5):64-70

[9]Moss Kevin B M. Ivan Refu, Alexeyev C H.Corrosion and protection of concrete and reinforced concrete[M].Beijing: Chemical Industry Press,1998

[10]Zhang Yu, Jiang Lixue. A practical mathematical model of concrete carbonation depth based on the mechanism[J].Industrial construction,1998,28(1):16- 19,47

[11]Dong Zhenping, Niu Ditao, Liu Xifang, et al.Calculation method of the initial time of steel-bar corrosion under atmospheric environment[J].Journal of Xi'An university of Architecture and Technology(Natural Science Edition), 2006,38(2):204-209

[12]Liu Yaqin. A Practical Calculating Model of Reinforcement Corrosion Induced by Concrete Carbonation[D]. Shanghai: Tongji University, 1997

[13]Jiang Lixue.Methematical Modeling and Experimental Investigation of Concrete Carbonation[D]. Shanghai: Tongji University,1996

[14]Yuan Chengbin, Zhang Defeng, Liu Ronggui, et al. Concrete Carbonation under different stress state[J].Building Structure, 2004,34(4):32- 34

[15]V.G.Papadakis, C.G.Vayenas, M.N.Fardis. Fundamental Modeling and Experimental Investigation of Concrete Carbonation[J]. ACI Materials Journal, 1991, 88(4):363-373

[16] V.G.Papadakis, C.G.Vayenas, M.N.Fardis. Physical and Chemical Characteristics Affecting the Durability of Concrete[J]. ACI Materials Journal, 1991,8(2):186-196

[17]Hong Naifen. Alkalinity of concrete and steel corrosion [J].concrete and cement products, 1990,5:16-18

[18]V.G.Papadakis, C.G.Vayenas, M.N.Fardis.A Reaction Engineering Approach to the Problem of Concrete Carbonation[J].AIChE Journal, 1989,35(10):1639-1650

[19]Wang Yuanzhan, Tian Shuangzhu, Wang Jun, et al. Chloride diffusion model of RC member in various marine environments considering loading effect[J].Journal of Waterway and Harbor, 2010, 31(2): 125-131

[20] M D A Thomas, E C Bentz. Life-365 Service Life Prediction Model and Computer Program for Predicting the Service Life and Life-cycle Costs of Reinforced Concrete Exposed to Chlorides,2001 [21] Mangat P S, Gurusamy K. Chloride Diffusion in Steel Fiber Reinforced Concrete Containing $\mathrm{Pfa}[\mathrm{J}]$. Cement and Concrete Research, 1978, 17(4):640-650 
[22] Code for Durability Design of Concrete Structures[S](GBT50476-2008)

[23]Jiangxi environmental quality monthly report form 2008 to 2013 (from the Jiangxi provincial government information disclosure network) 